Journal of Advanced Research in Fluid Mechanics and Thermal Sciences

Journal homepage: www.akademiabaru.com/arfmts.html ISSN: $2289-7879$

\title{
Prediction and Performance Investigation of Polyurethane Foam as Thermal Insulation Material for Roofing Sheet Using Artificial Neural Network
}

\author{
V. B. Essien ${ }^{1}$, Christian A. Bolu², Imhade P. Okokpujie ${ }^{1,}{ }^{*}$, Joseph Azeta ${ }^{1}$ \\ Department of Mechanical Engineering, Covenant University, Ota, Ogun State, Nigeria \\ Department of Mechatronics Engineering School of Science and Technology, Pan-Atlantic University, Lagos State, Nigeria
}

\section{ARTICLE INFO}

\section{Article history:}

Received 22 December 2020 Received in revised form 10 March 2021 Accepted 13 March 2021

Available online 14 April 2021

\section{Keywords:}

Artificial neural network; polyurethane foam; residential roofing system; thermal insulation material

\section{ABSTRACT}

\begin{abstract}
The prediction and application of Polyurethane Foam in developing roofing sheets cannot be over-emphasized when considering the environmental changes caused by thermal radiation. This paper presents an artificial neural network (ANN) application to model and predict the indoor temperature resistance of polyurethane (PU) roofing in residential buildings. The study employed a data logger to measure the indoor and outdoor temperatures for three simulation environments (i.e., morning, afternoon, and evening) for two hours each. Furthermore, the authors employed the LevenbergMarquardt algorithm to transform and predict the indoor temperature obtained in the residential building's polyurethane roofing house. The result shows that the PU roofing system could absorb the heat and reduce the house model's temperature with $6.9 \%$ in the morning, afternoon $15.8 \%$, and $6.8 \%$ in the evening compared with the temperature outdoor environment. The ANN was also able to train, test, and validate the experimental temperature results with $92.86 \%, 93.92 \%$, and $95 \%$, respectively. The mean square error and a testing error occurs at 0.1707 and 0.1689 . Therefore, this study concluded that the ANN's application in predicting the thermal insulation material such as the PU roofing system is highly efficient. And will increase the manufacturer's performance evaluation. It has also created significant awareness of the community in employing the PU roofing system for residential buildings, which will reduce the rate of energy consumption in buildings.
\end{abstract}

\section{Introduction}

The building industry contributes the largest to energy consumption in the world. There is an energy expectation demand of up to $50 \%$ by 2050 if appropriate sanctions are not implemented [1]. The various underlying issues in the environment have led to an in-depth study of discovering techniques for better and efficient energy management. It also saves in residential and commercial buildings to reduce $\mathrm{CO}_{2}$ emissions, generating a green-house effect [2]. One primary objective for buildings is the reduction in energy demands. This contributes a significant amount to the overall

\footnotetext{
* Corresponding author.

E-mail address: imhade.okokpujie@covenantuniversity.edu.ng
}

https://doi.org/10.37934/arfmts.82.1.113125 
emission of $\mathrm{CO}_{2}$ in the environment globally, which is about a quarter of the total emission [3]. The energy consumption structure of the building helps to determine thermal performance. It is the key component that constitutes energy consumption, and reason walls, roofs, and floors thermally insulated can suitably reduce energy consumption [4].

Conserving energy in buildings has presented itself as a significant factor in this present time and day. This is brought about by increasing energy utilization in various commercial and residential establishments. The installed heating and cooling systems are usually made available in these houses to provide a more soothing and healthy environment. In 2016, 39.5\% of available energy in the world was preferably used for heating and cooling of buildings. ASHRAE [5] has defined thermal comfort as "the condition of the mind in which satisfaction is expressed with the thermal environment" [6]. The human body undergoes numerous chemical reactions to keep the body performing at an optimum rate, which results in huge amounts of heat being lost to the surrounding through the evaporation of body fluids. This is achieved when the heat rate produced is equivalent to the rate at which it is dissipated. Whenever the ambient temperature is significantly higher than the body's temperature, this constitutes body heat not being dissipated to the environment. It aids thermal comfort. So in whatever situation where air conditioners are turned on, it reduces the indoor temperature and proper body heat dissipation to attain thermal comfort [7].

Overtime, recent development has seen the use of innovative techniques for modelling thermal systems. ANN is among these new methods for analysing various parts of the building sector [8]. Employing ANN with a novel methodology, Deng and Chen [9] incorporated different roofs in the study, obtaining analytical models to efficiently fore-cast wind pressure coefficient in walls. Xu et al., [10] Developed an artificial neural network that uses the building's occupants' behaviour and thermal sensations to predict thermal comfort. Mohandes et al., [11] were able to predict the energy in multibuildings through an artificial neural network. However, this particular novel methodology had a prediction accuracy of $90.67 \%$. Kim et al., [12] reviewed applications of artificial neural networks in buildings. The results revealed the accuracy of the artificial neural network model, with its ease of application and ability to prevail under failure. Bui et al., [13] employed an artificial neural network for predicting energy consumption in residential buildings. This study revealed that the degree of ANN accuracy using the following parameters, including the house's direction, number of occupants, and period, was occupied. [14] an artificial neural network hybrid model was used to estimate the heating and cooling load. The firefly algorithm was used in this study and later compared to other methods. The results obtained revealed the firefly algorithm's contribution in designing energyefficient buildings, particularly in the early stage. Nivine et al., [15] used an artificial neural network to predict hourly the house model's indoor temperature made of a hollow cement block. These reviews show that researching thermal analysis of insulation materials is very significant and can increase and maintain the sustainability of the product's economic value [16-19]. However, this application has not been studied in south-south Nigeria.

Hence, this study aims to predict the PU roofing system's performance analysis using ANN to forecast the future and determine the house model's accuracy with the data logger, which has not been studied. The levenberg-Marquardt algorithm using MATLAB was utilized in this particular research. The coefficient of correlation for the air temperature and relative humidity are 0.9850 and 0.9853, respectively. An artificial neural network model was developed in forecasting the indoor temperature. The model used the outdoor temperature and the façade temperature in predicting indoor temperature, which will help for optimal control of the building energy devices. 


\section{Methodology}

\subsection{Experimental Set-Up}

In order to effectively analyse the thermal performance of the polyurethane aluminium roofing system, a house-model was designed and built. The embedded PU foam roofing sheet and the housemodel are shown in Figure 1(a) and 1(b). The house model was built outside, with complete exposure to solar radiation, as shown in Figure 1(b). Table 1 shows the various parameters used to developed the house model.

Table 1

Design parameters of house model

\begin{tabular}{ll}
\hline Block Length & $0.44 \mathrm{~m}$ \\
\hline Block Width & $0.15 \mathrm{~m}$ \\
Height of Aluminium Polyurethane Embedded Roof & $1.26 \mathrm{~m}$ \\
Width of Aluminium Polyurethane Embedded Roof & $1.51 \mathrm{~m}$ \\
\hline
\end{tabular}

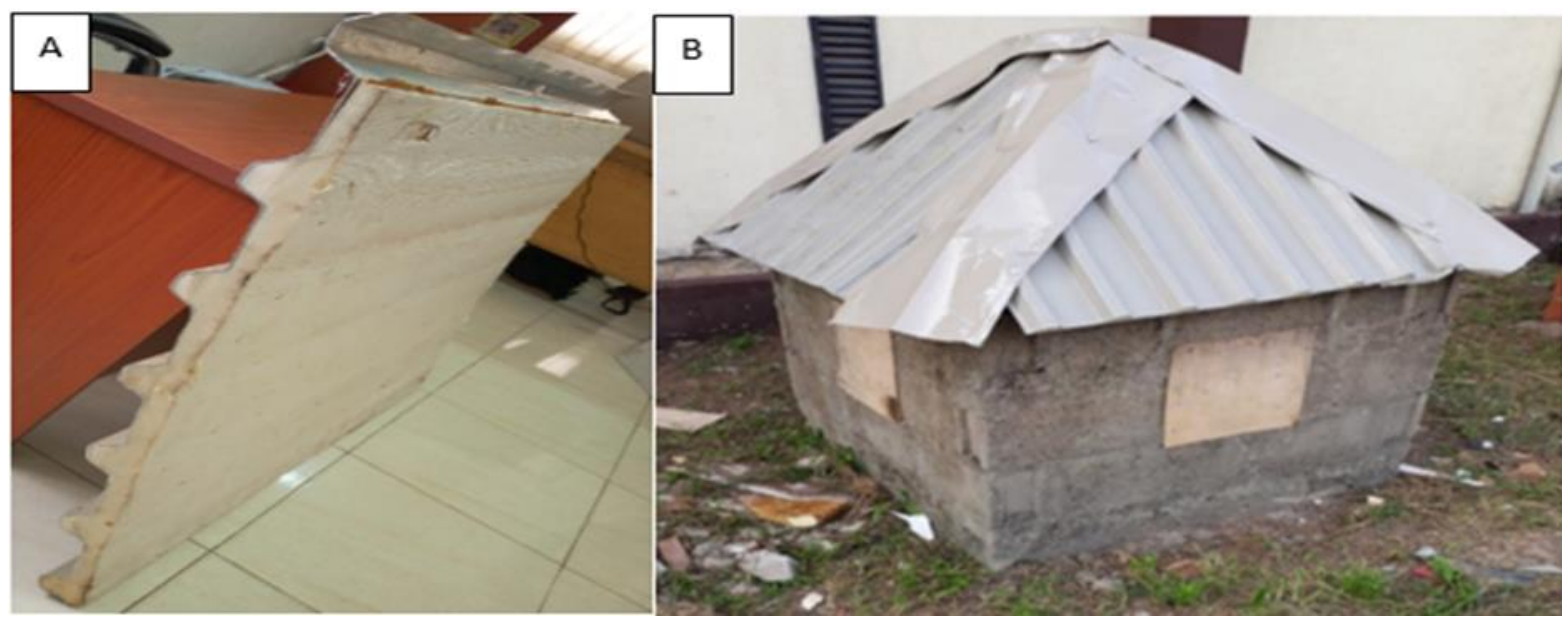

Fig. 1. (a) The PU embedded aluminium roofing (b) Experimental set-up of house model with aluminium polyurethane foam roofing system

\subsection{Instrumentation and the Procedure Used for the Optimization and Prediction of The ANN Result}

The data logger shown in Figure 2 was attached to the house-model to obtain specific parameters for this research, which were the indoor temperature and the outdoor temperature with a particular time where each temperature value was written to the SD Card. The data logger used in this research was developed to perform the authors' task and operations in obtaining the parameters.

Artificial Neural Network terms to perform typical tasks that would be performed by the brain. It has proved a real significant ability in resolving various modeling problems [20]. The processing units in ANN is referred to as Neurons. Neural Network operation can be generalized with the following equations.

$$
\begin{aligned}
& n_{k}=\sum_{j=1}^{m}\left(w_{k j}\right)+b_{k} \\
& y_{k}=\varphi\left(d_{k}\right)\left(n_{k}\right)
\end{aligned}
$$


$k j$ is considered an input, which is multiplied with the weight $w_{k j}$ and then added to $b_{k}$ representing the external bias. $n_{k}$ stands for the network, $d_{k}$ represents the summed data output and $y_{k}$ Is the signal output. In order to control the amplitude range of $y_{k}$ the activation function $\varphi$ is used. The $\varphi$ is used in this research as the sigmoid function and is expressed as follows

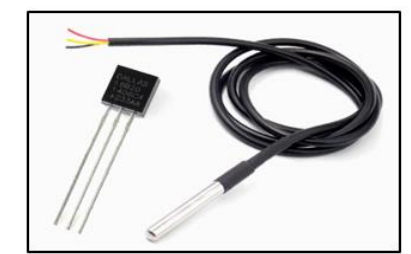

(a) DS18B20 Temp. Sensor

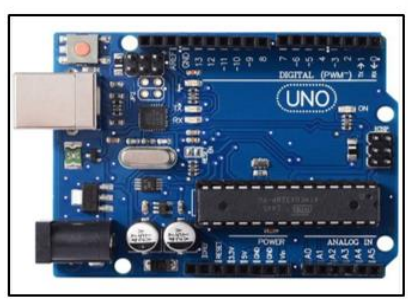

(b) Arduino Uno R3

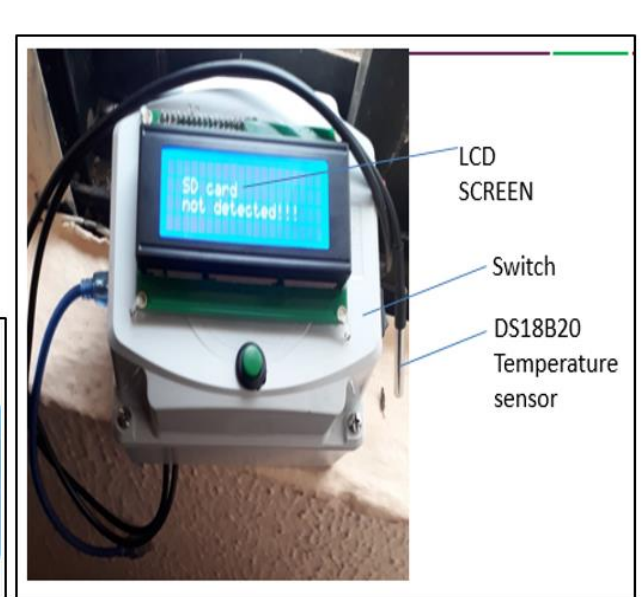

Temperature ensor

Fig. 2. Developed data-logger with embedded components

$\varphi\left(d_{k}\right)=\frac{1}{1+e^{-d_{k}}}$

It is the most commonly used activation function. ANNs are set-up using different model types. The multi-layer perceptron (MLP) is the model type used in this research. The schematic diagram for the MLP is represented in Figure 3. This is the necessary foundation in setting up all neural network models. There are usually one or more hidden layers. This all depends on the type of architecture required with a single input and a single output layer. The model depends on the input data's functionality, and this data is work on by the hidden layer, thereby generating the output. The user collects the output at the output layer. All neurons are interconnected, and this makes output generation possible. MLP is also referred to as the feed-forward neural network. For the input layer, the neuron output is given as Eq. (4).

$$
\text { Out }_{i, k_{i}}=f\left(\sum_{p=0}^{P} w_{p k_{i}} x_{p}\right), k_{i}=1, \ldots, K_{i}
$$

where $P$ stands for the number of neurons at the input layer. The output layer was fed into a hidden neuron in the hidden layer, is given in Eq. (5)

$$
\text { Out }_{h, k_{h}}=\varphi\left(\sum_{K_{h-1}=0}^{K_{h-1}} w_{k_{h-1}, k_{h}} \text { Out }_{h-1, k_{h-1}}\right)
$$

where $\varphi$ Represents the activation function

$K_{h}$ Furthermore, $P$ is the number $h t h$ of the hidden layer neuron and its inputs, respectively. $N_{h}$ is the number of hidden layers. The output generated at the output layer is achieved by adding the outputs generated at the hidden layer; this is expressed as

$y_{t}=\sum_{k_{N}=0}^{K_{N}} w_{K N, t} O u t_{N, k_{N}}, t=1, \ldots T$ 
where $T$ the total number of neurons in the output layer is, $w_{k_{h}, t}$ is the weight of the connecting link of the hidden layer. The Multi-layer perceptron will be trained using the back-propagation algorithm. This helps for easy adjustment of the weights of the network, thus generating appropriate output. One such training algorithm, the Levenberg Marquardt (LM), is utilized in this research. Levenberg Marquardt is a standard and useful algorithm used for training artificial neural network models. It has a damping factor $\lambda$, which can be altered from time to time to obtain the least mean square error. The LM rule can be expressed as follows

$w_{k+1}=w_{k}-\left(J_{k}^{T} J_{k}+\lambda I\right)^{-1} J_{k} e_{k}$

$w$, stands for the weights,

$J$, represents the Jacobian matrix shown below,

$J=\left[\begin{array}{cccc}\frac{\partial e_{1}(w)}{\partial w_{1}} & \frac{\partial e_{1}(w)}{\partial w_{2}} & \ldots & \frac{\partial e_{1}(w)}{\partial w_{n}} \\ \frac{\partial e_{2}(w)}{\partial w_{1}} & \frac{\partial e_{2}(w)}{\partial w_{2}} & \ldots & \frac{\partial e_{2}(w)}{\partial w_{n}} \\ \vdots & \vdots & \ddots & \vdots \\ \frac{\partial e_{N}(w)}{\partial w_{1}} & \frac{\partial e_{N}(w)}{\partial w_{2}} & \ldots & \frac{\partial e_{N}(w)}{\partial w_{n}}\end{array}\right]$

Je, stands for the error gradient.

The entire process for the ANN structure in the MATLAB environment is shown in Figure 4 and 5. It represents all tasks carried out to develop the indoor temperature prediction model. In any situation where there are unsatisfactory outcomes, network architecture is adjusted.

For this research, the MLP ANN model using LM was developed in MATLAB for predicting the indoor temperature of a building model with an aluminium roofing sheet embedded with polyurethane foam. The model is comprised of three layers: the input, the hidden layer, and an output layer. In this study, the input layer consists of two neurons; each was representing an input variable. The input variables utilized in this model are presented in Table 2 . These input parameters represent constraints that could influence the indoor thermal comfort in the building model. Having (10) neurons in the hidden layer is determined by the best design fit approach. The output layer has one neuron representing the output, which is the indoor temperature. The Sigmoid activation function was utilized as an activation function at the hidden layer and the output layer.

$y=f\left(x_{1}, x_{2}\right)$

\section{Table 2}

The input variables utilized in this model

\begin{tabular}{llll}
\hline Annotation & Inputs & Units & Meaning \\
\hline XI & Time of Day & Minutes & This represents the exact time recorded. \\
X2 & $\begin{array}{l}\text { Outdoor } \\
\text { Temperature }\end{array}$ & Degree Celsius & This represents the outdoor temperature at the time recorded \\
& & \\
\hline
\end{tabular}


The mapping between the output and the input variables at the hidden layer and output layer can be expressed as follows

Hidden Layer $\rightarrow n_{k}^{(1)}=\sum_{n=1}^{R} w_{k n}^{(1)} x_{n}+b_{k}^{(1)}$

Output Layer $\rightarrow n_{k}^{(2)}=\sum_{n=1}^{R} w_{k n}^{(2,1)} f_{1 \text { Level }}\left(n_{k}^{(1)}\right)+b_{1}^{(2)}$

$y=f_{2 \text { Level }}\left(n_{k}^{(2)}\right)$

$y_{*}=f_{*}\left(\sum_{k=1}^{N} w_{k}^{\prime} f\left(\sum_{n=1}^{R} w_{k n} x_{n}+b_{k}^{(1)}\right)+b^{(2)}\right) ; n=1,2 \ldots R k=1,2 \ldots, N$

$y_{*}$ is the overall equation of the output layer after several iterations have been done. Moreover, the schematic diagram of the neural network model utilized in this research is presented in Figure 4.

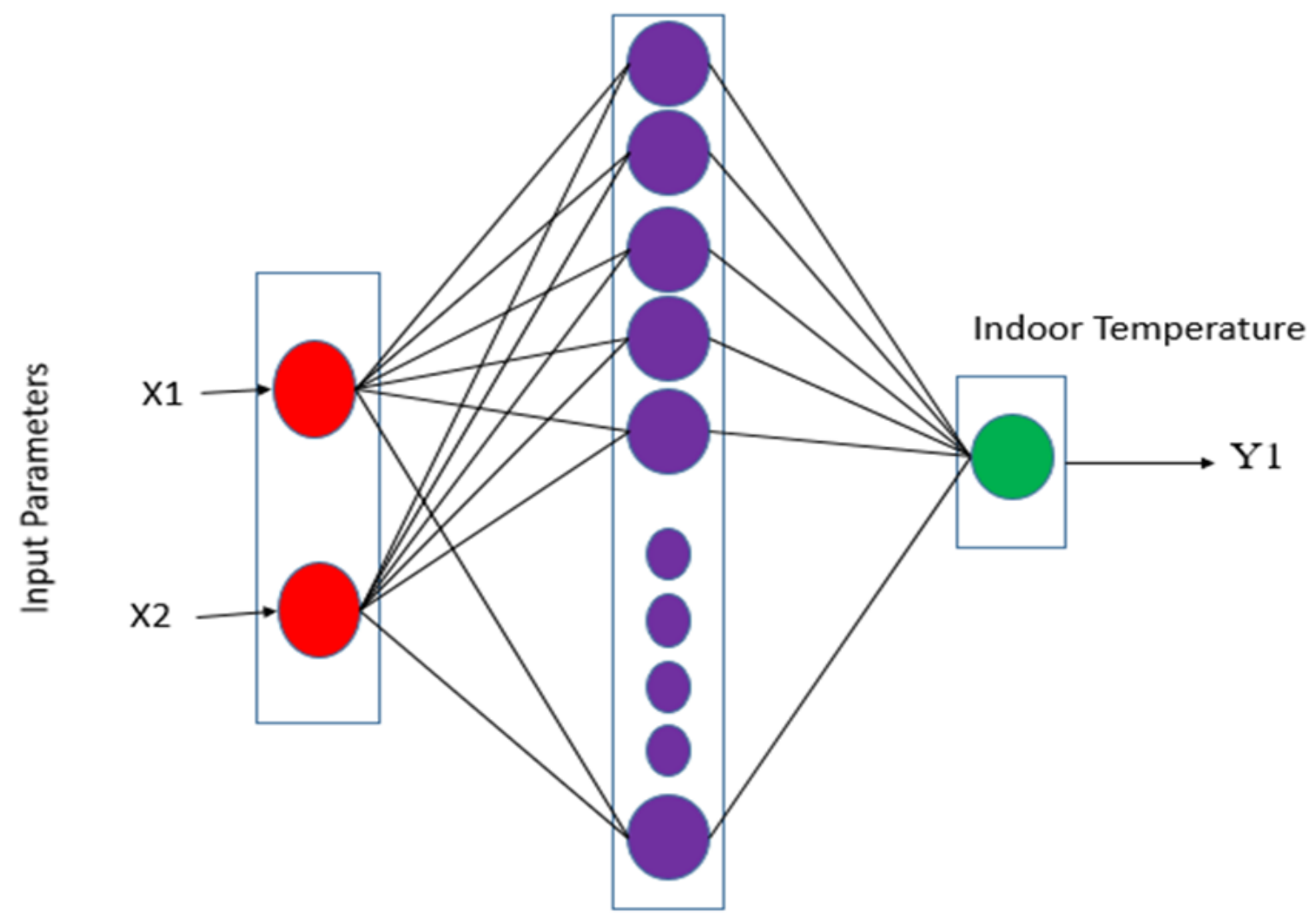

Input Layer

Hidden Layer

Output Layer

Fig. 3. MLP schematic neural network utilized in this research 


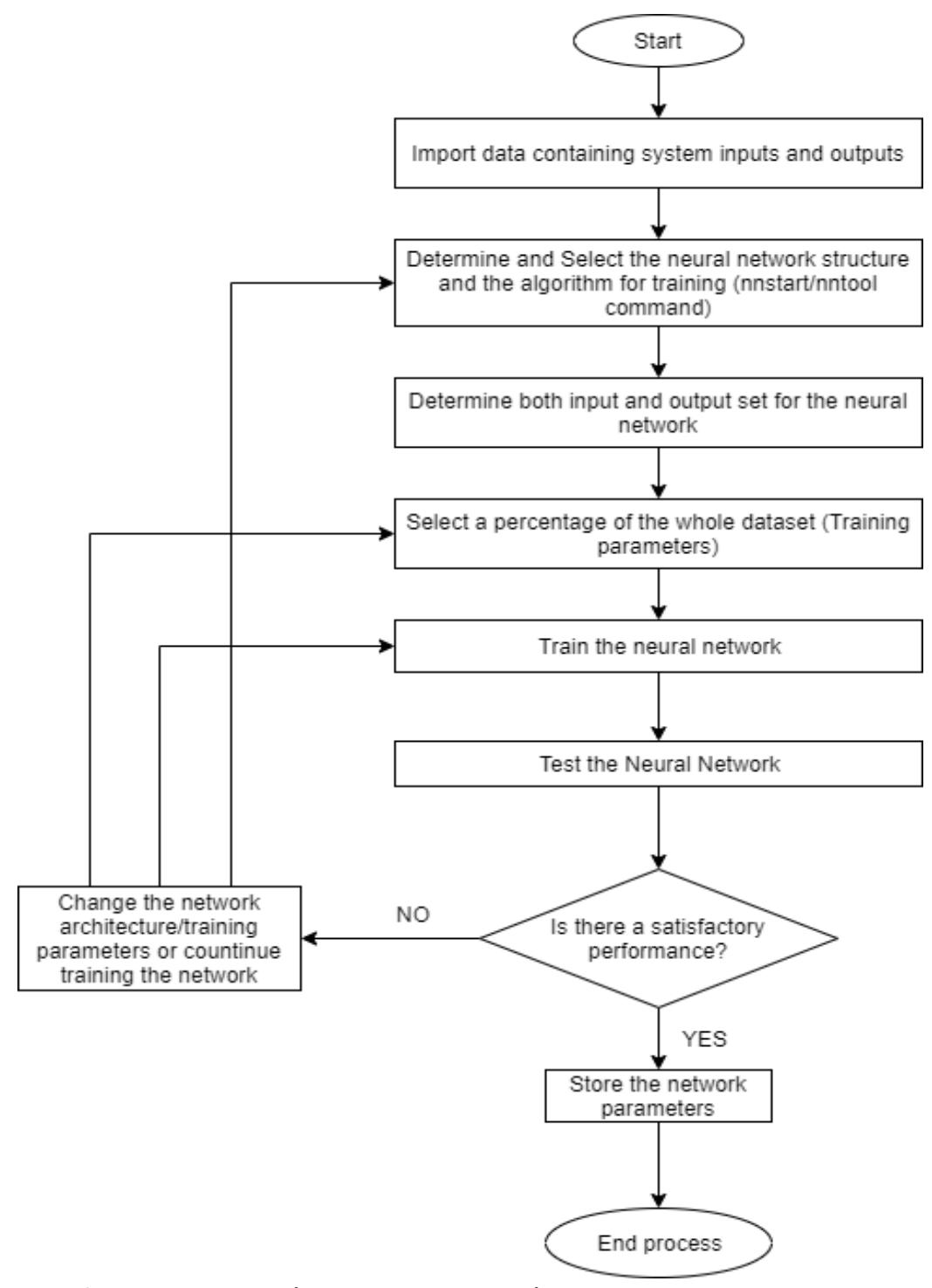

Fig. 4. ANN simulation process in the MATLAB environment

\section{Result and Discussion}

The result obtained from the experimental insulation analysis is shown in Figure 5, which also presents the comparative analysis of the morning environment's outdoor temperature and indoor temperature. After each two hours variation period, which was from 7:05 am - 9:00 am. It was observed that the polyurethane foam was able to reduce the ambient temperature by $6.9 \%$ for optimal indoor thermal comfort. In Figure 6, the comparative analysis shown is for the afternoon environment for the polyurethane aluminium roofing system's thermal performance, which was for another two hours variation between 1:05 pm - 3:00 pm. There was, however, a 15.8\% reduction in the ambient temperature for optimal indoor thermal comfort. Figure 7 presents the evening thermal performance comparative analysis for another two hours variation between 18:05 - 20:00, and there was a $6.8 \%$ reduction in the outdoor temperature for optimal indoor thermal comfort. 


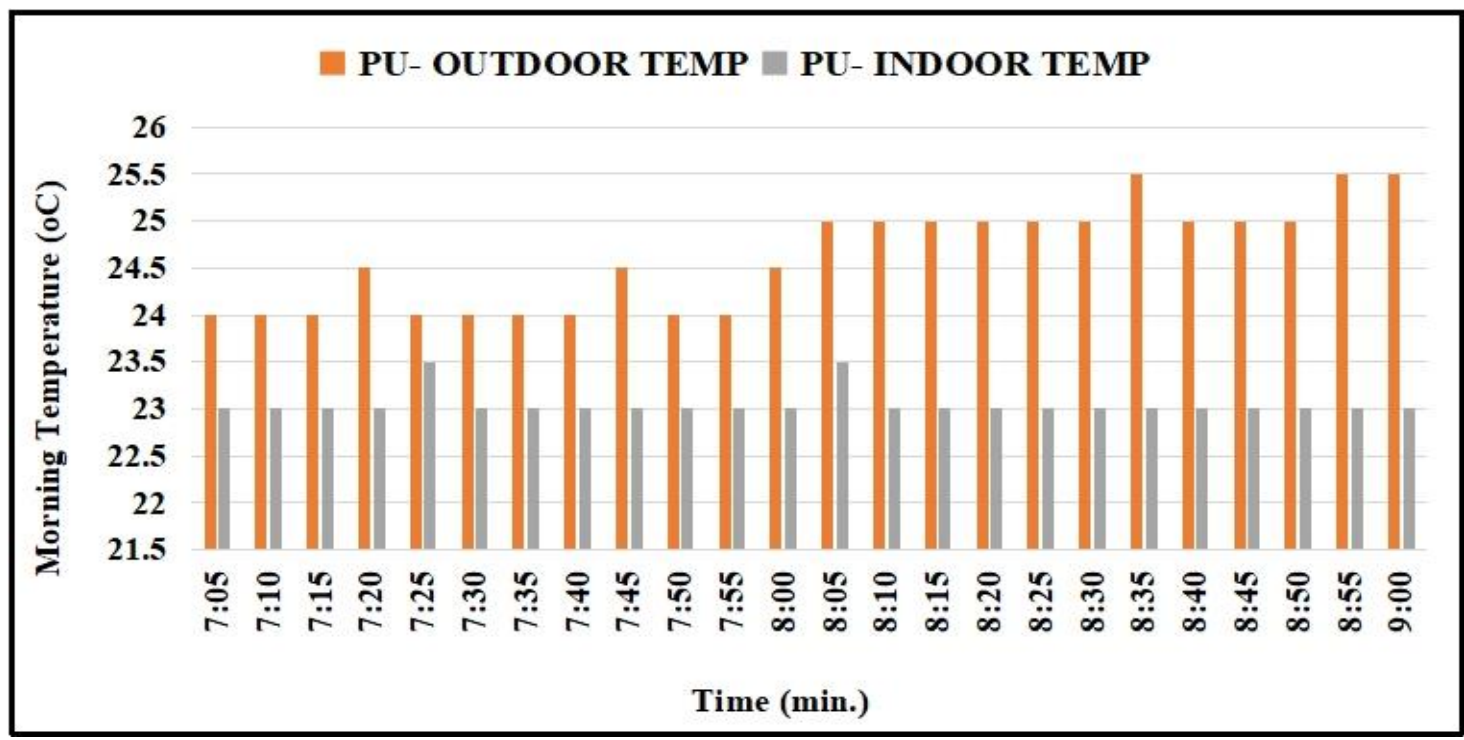

Fig. 5. Outdoor vs. indoor temperature for the PU aluminium roofing morning environment

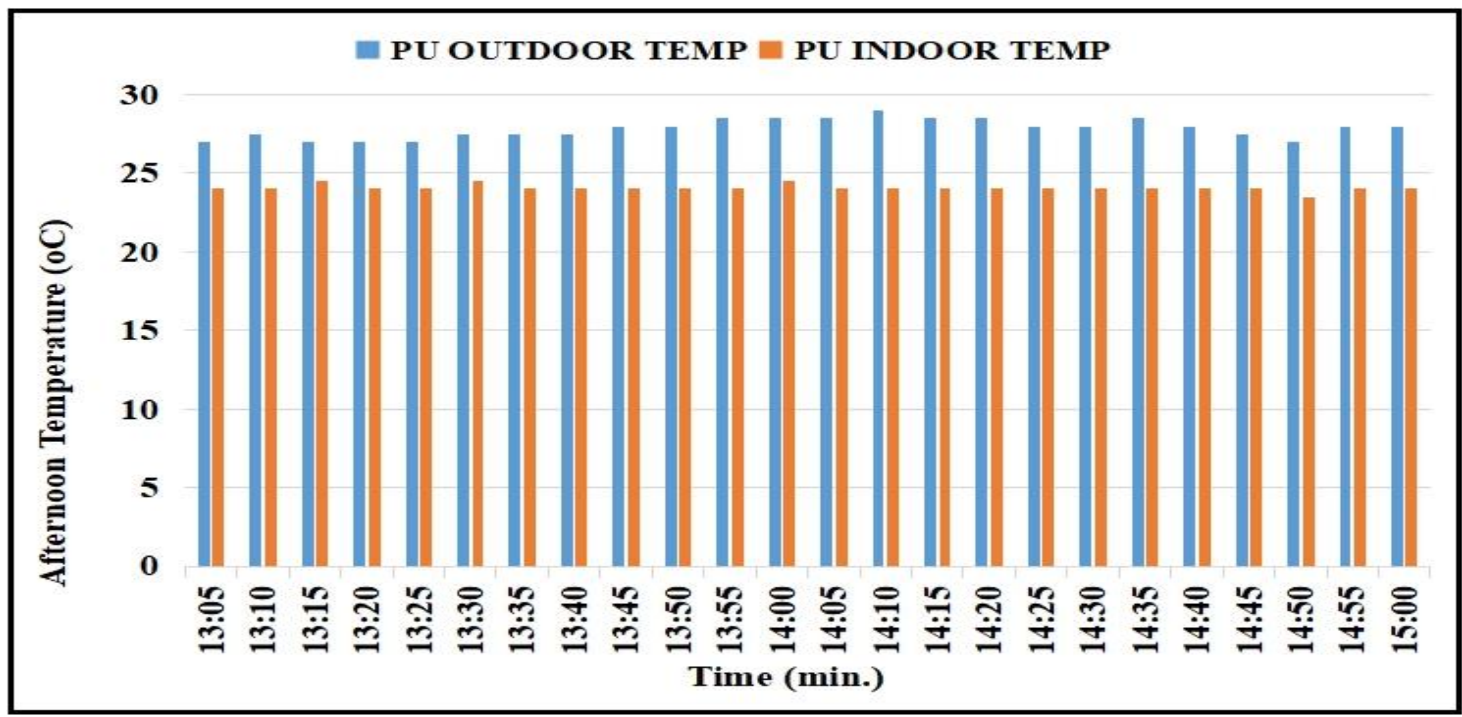

Fig. 6. Outdoor vs. indoor temperature for the PU aluminium roofing afternoon environment

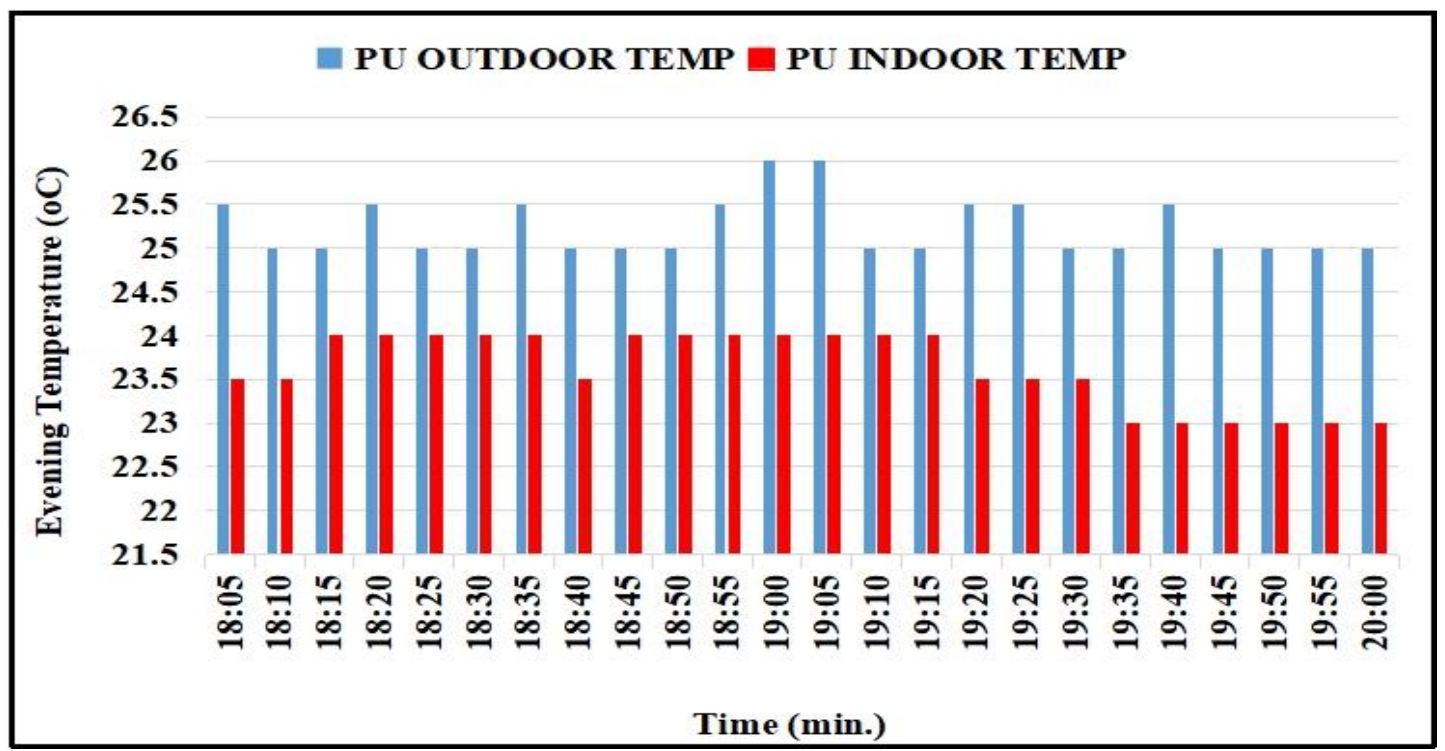

Fig. 7. Outdoor vs. indoor temperature for the PU aluminium roofing evening environment 


\subsection{Result of ANN Prediction Analysis of PU-Al Roofing System}

In this research, the "nftool" in MATLAB is used to develop a model to predict the indoor temperature in a house model with aluminium-polyurethane foam sandwich panels. The training algorithm was carried out through a heuristic approach in order to attain the best parameters. The data utilized in this research to build the model was obtained from a data logger attached to DS18B20 temperature sensors placed inside a house model for five (5) days. The data obtained was further divided into training, testing, and external testing datasets. At the end of this study, three-hundred and sixty (360) data were obtained for five days. Out of this number, two-hundred and fifty-two (252) data samples were used in training the network. The remaining one-hundred and eight (108) were used to carry out further tests. Testing can be subdivided into validation and testing, and this is dependent on the training algorithm used. Fifty-four (54) data samples were separated and used to perform an external test after the model has been developed (Fit to the network, trained, validated, and tested). $70 \%$ of the data were trained, $15 \%$ for testing, and $15 \%$ for validation.

The multi-layer perceptron (MLP) developed in this research to predict the house model's indoor temperature consists of three layers. The input layer, hidden layer, and output layer. The input layer has two (2) neurons, with each neuron representing an input variable listed above. The output layer has one neuron, which corresponds to the single output variable for these experimental results (value of the indoor temperature). The hidden layer has ten (10) neurons. This number was obtained using an empirical approach, knowing that the building and block sizes' sizes are constant. The model developed with the ANN is presented in Figure 8.

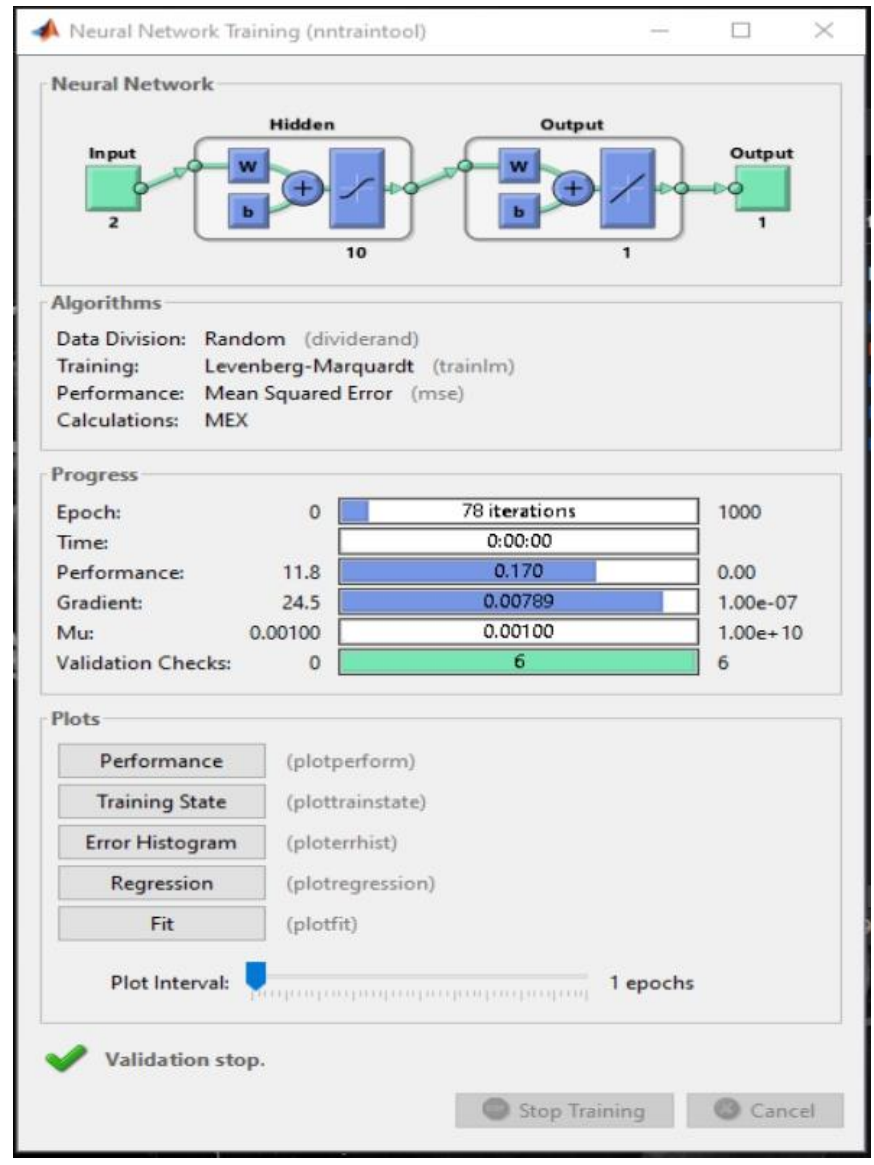

Fig. 8. Training simulation progress report 
The network calculates the errors on the training and testing dataset. The Artificial training iterations come to an end when it arrives at the least error, which shows the neural network can still function for a new dataset. The performance analysis is measured based on Regression (R) Mean Square Error (MSE). Regression analysis involves statistical processes for estimating the correlation between independent (predictors) and dependent variables (outcome variables). A model having a regression $(R)$ value of 1 is most desirable, while a model having an $R$-value of 0 is least desirable [21,22]. Table 3 shows this performance analysis of the MSE and R-value in a tabular form. Figure 9 to Figure 12 show a detailed plot of the model's regression analysis performance evaluation.

Table 3

MSE and R-value for the training and testing

\begin{tabular}{lll}
\hline & MSE & $\mathrm{R}$ \\
\hline Training & $1.70748 \times 10^{-1}$ & 0.9286 \\
Validation & $1.04068 \times 10^{-1}$ & 0.93919 \\
Test & $1.68892 \times 10^{-1}$ & 0.95045 \\
All & - & 0.93216 \\
\hline
\end{tabular}

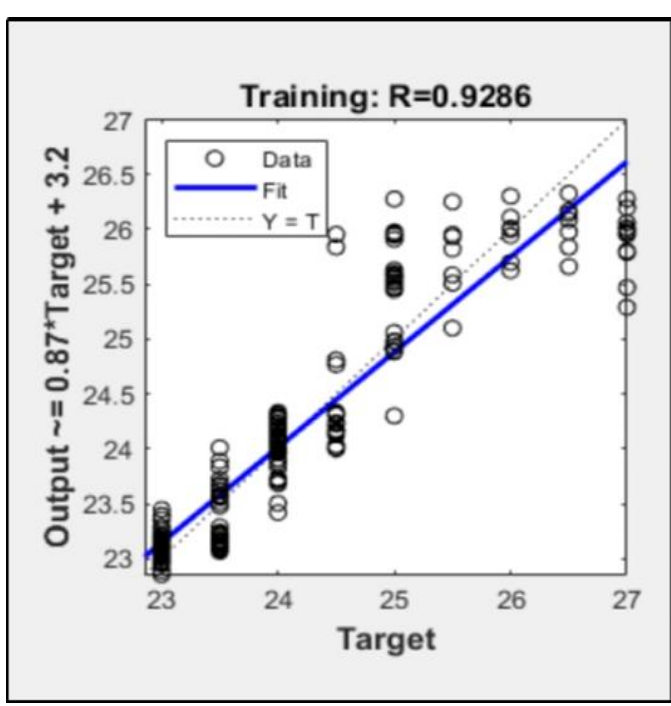

Fig. 9. ANN training model result analysis for the PU-AL-roofing system



Fig. 11. ANN validation model result analysis for the PU-AL-roofing system

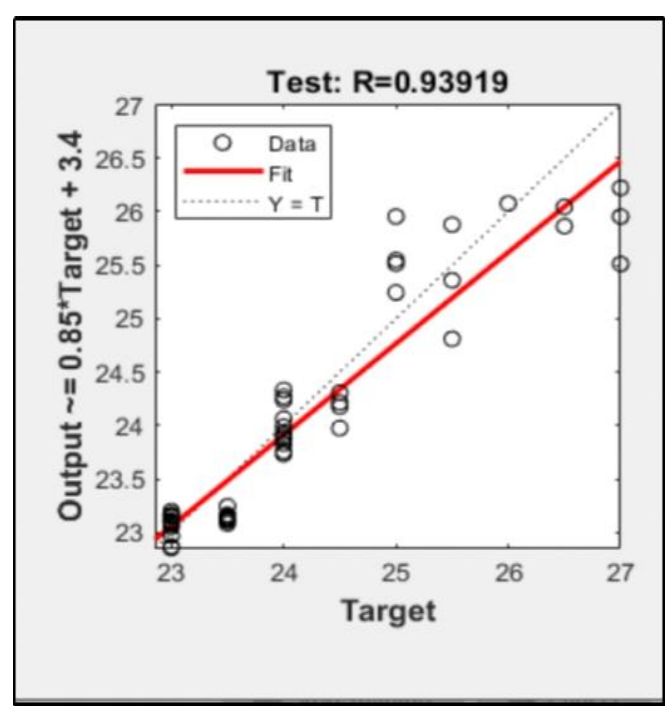

Fig. 10. ANN testing model result analysis for the PU-AL-roofing system

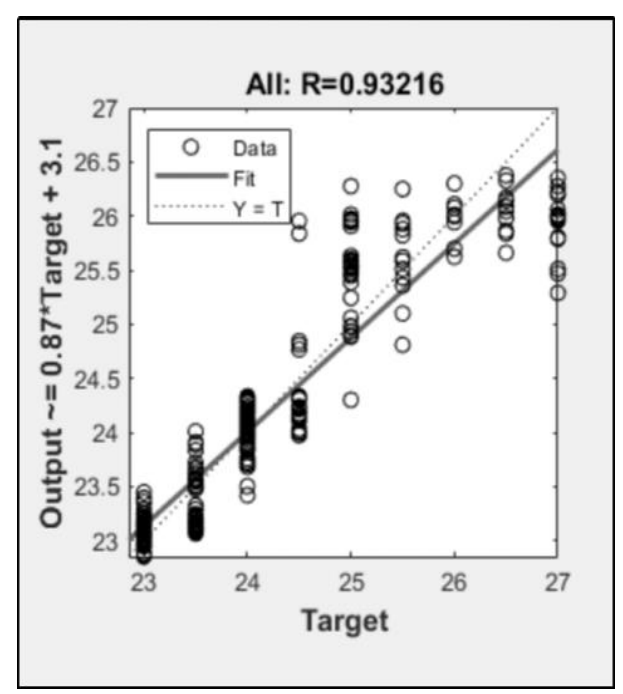

Fig. 12. ANN all performance model result for the PU-AL-roofing system 
Figure 13 shows the validation's best performance for the polyurethane aluminium roofing system with the best validation at 0.089424 at epoch 0 . Bins are the number of vertical bars, as shown in Figure 14. The neural network's total error ranges from -1.518 (leftmost bin) to 1.947 (rightmost bin).

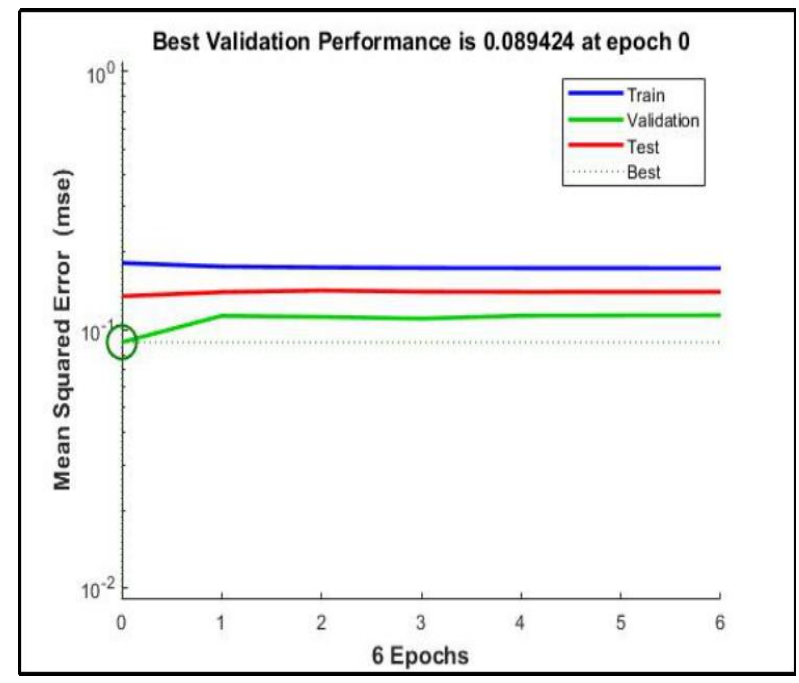

Fig. 13. ANN best validation model result for the PU-AL roofing system

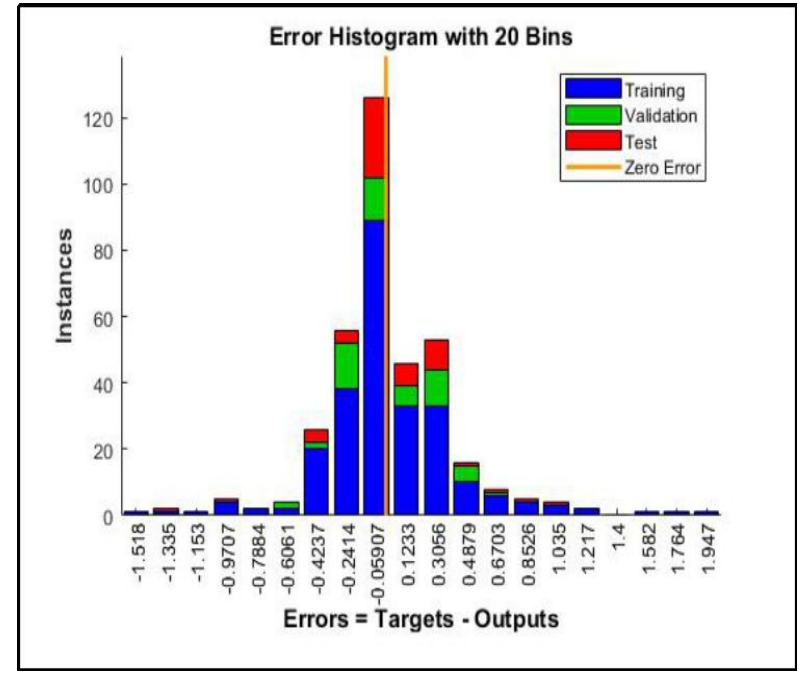

Fig. 14. ANN error analysis of the predicted result for the PU-AL-roofing system

This error range is divided into 20 smaller bins, so each bin has a width of $\frac{1.947-(-1.518)}{20}=0.1732$. Figure 6 to 8 present the temperature values for the outdoor and indoor temperature obtained via the data logger during the over-all five-day period and the artificial neural network predictions for the indoor temperature. The study has shown that there need to conserve energy consumption by using a PU roofing system, which is in line with the study of [23-25]. The authors surveyed the alternative application of nanoparticles in increasing the cooling rate within the house environment for human comforts. Furthermore, work on applying developed wood-polypropylene plastic-cement for building roofing system to suit eco-friendly materials [26-28]. This study has carried out using PU form in creating the roofing system for thermal comfort.

\section{Conclusion}

This study has successfully analysed and evaluated the effects of polyurethane aluminium roofing systems in the Covenant University community to study its cooling comfort. Also, predict its performance using the artificial neural network with the outdoor and indoor temperature. Therefore, the study has the following conclusion

i. The polyurethane aluminium roofing system assists the building in distributing the heat uniformly across the environment. Also, there was a significant reduction in the indoor temperature. The polyurethane foam embedded in the roof serves as a very efficient insulation material.

ii. The optimized resistance period for the polyurethane aluminium roofing system to absorb the heat radiation before reacting is between 45 to 60 minutes, with a minimum of $23^{\circ} \mathrm{C}$.

iii. The artificial neural network employed predicted the indoor house model's thermal insulation experimental result with $95 \%$. This accurate prediction has proven that ANN can serve in future energy management analysis. 
However, it will also help predict the indoor temperature for a particular outdoor temperature at a specific time to convince customers to purchase the roofing system.

\section{References}

[1] Judkoff, Ron, and Joel Neymark. International Energy Agency building energy simulation test (BESTEST) and diagnostic method. No. NREL/TP--472-6231. National Renewable Energy Lab., 1995. https://doi.org/10.2172/90674

[2] Sierra-Pérez, Jorge, Jesús Boschmonart-Rives, and Xavier Gabarrell. "Environmental implications in the substitution of non-renewable materials by renewable materials." SETAC Europe 2015 (2015).

[3] Miezis, Martins, Kristaps Zvaigznitis, Nicholas Stancioff, and Lars Soeftestad. "Climate change and buildings energy efficiency-the key role of residents." Environmental and Climate Technologies 17, no. 1 (2016): 30-43. https://doi.org/10.1515/rtuect-2016-0004

[4] Aditya, Lisa, T. M. I. Mahlia, B. Rismanchi, H. M. Ng, M. H. Hasan, H. S. C. Metselaar, Oki Muraza, and H. B. Aditiya. "A review on insulation materials for energy conservation in buildings." Renewable and sustainable energy reviews 73 (2017): 1352-1365. https://doi.org/10.1016/i.rser.2017.02.034

[5] Olesen, Bjarne W., and Gail S. Brager. "A better way to predict comfort: The new ASHRAE standard 55-2004." (2004).

[6] Ong, Kok Seng. "Temperature reduction in attic and ceiling via insulation of several passive roof designs." Energy Conversion and Management 52, no. 6 (2011): 2405-2411. https://doi.org/10.1016/i.enconman.2010.12.044

[7] Kumar, Rajesh, R. K. Aggarwal, and J. D. Sharma. "Energy analysis of a building using artificial neural network: A review." Energy and Buildings 65 (2013): 352-358. https://doi.org/10.1016/i.enbuild.2013.06.007

[8] Bre, Facundo, Juan M. Gimenez, and Víctor D. Fachinotti. "Prediction of wind pressure coefficients on building surfaces using artificial neural networks." Energy and Buildings 158 (2018): 1429-1441. https://doi.org/10.1016/i.enbuild.2017.11.045

[9] Deng, Zhipeng, and Qingyan Chen. "Artificial neural network models using thermal sensations and occupants' behavior for predicting thermal comfort." Energy and Buildings 174 (2018): 587-602. https://doi.org/10.1016/i.enbuild.2018.06.060

[10] Xu, Xiaodong, Wei Wang, Tianzhen Hong, and Jiayu Chen. "Incorporating machine learning with building network analysis to predict multi-building energy use." Energy and Buildings 186 (2019): 80-97. https://doi.org/10.1016/i.enbuild.2019.01.002

[11] Mohandes, Saeed Reza, Xueqing Zhang, and Amir Mahdiyar. "A comprehensive review on the application of artificial neural networks in building energy analysis." Neurocomputing 340 (2019): 55-75. https://doi.org/10.1016/i.neucom.2019.02.040

[12] Kim, Mansu, Sungwon Jung, and Joo-won Kang. "Artificial neural network-based residential energy consumption prediction models considering residential building information and user features in South Korea." Sustainability 12, no. 1 (2020): 109. https://doi.org/10.3390/su12010109

[13] Bui, Dac-Khuong, Tuan Ngoc Nguyen, Tuan Duc Ngo, and H. Nguyen-Xuan. "An artificial neural network (ANN) expert system enhanced with the electromagnetism-based firefly algorithm (EFA) for predicting the energy consumption in buildings." Energy 190 (2020): 116370. https://doi.org/10.1016/i.energy.2019.116370

[14] Mba, Leopold, Pierre Meukam, and Alexis Kemajou. "Application of artificial neural network for predicting hourly indoor air temperature and relative humidity in modern building in humid region." Energy and Buildings 121 (2016): 32-42. https://doi.org/10.1016/i.enbuild.2016.03.046

[15] Attoue Nivine, Shahrour Isam, and Younes Rafic. "Smart Building: Use of the ANN Approach for Indoor Temperature Forecasting." Energies 11 (2018). https://doi.org/10.20944/preprints201801.0051.v1

[16] Okokpujie, Imhade P., O. S. I. Fayomi, and R. O. Leramo. "The role of research in economic development." In IOP Conference Series: Materials Science and Engineering, vol. 413, no. 1, p. 012060. IOP Publishing, 2018. https://doi.org/10.1088/1757-899X/413/1/012060

[17] Oyekunle, J. A. O., J. O. Dirisu, Imhade P. Okokpujie, and A. A. Asere. "Determination of Heat Transfer Properties of Various PVC and Non-PVC Ceiling Materials Available in Nigerian Markets." International Journal of Mechanical Engineering and Technology (IJMET) 9, no. 8 (2018): 963-973.

[18] Dunmade, Israel, Mfon Udo, Tunde Akintayo, Sunday Oyedepo, and Imhade P. Okokpujie. "Lifecycle impact assessment of an engineering project management process-a SLCA approach." In IOP conference series: materials science and engineering, vol. 413, no. 1, p. 012061. IOP Publishing, 2018. https://doi.org/10.1088/1757899X/413/1/012061

[19] Lee, Do-Hun, and Doo-Sun Kang. "The application of the artificial neural network ensemble model for simulating streamflow." Procedia engineering 154 (2016): 1217-1224. https://doi.org/10.1016/i.proeng.2016.07.434 
[20] Wang, Yu-Ren, and G. Edward Gibson Jr. "A study of preproject planning and project success using ANNs and regression models." Automation in Construction 19, no. $3 \quad$ (2010): $341-346$. https://doi.org/10.1016/j.autcon.2009.12.007

[21] Gazzaz, Nabeel M., Mohd Kamil Yusoff, Ahmad Zaharin Aris, Hafizan Juahir, and Mohammad Firuz Ramli. "Artificial neural network modeling of the water quality index for Kinta River (Malaysia) using water quality variables as predictors." Marine pollution bulletin 64, no. $11 \quad$ (2012): $2409-2420$. https://doi.org/10.1016/i.marpolbul.2012.08.005

[22] Murphy, Kevin R., Brett Myors, and Allen Wolach. Statistical power analysis: A simple and general model for traditional and modern hypothesis tests. Routledge, 2014. https://doi.org/10.4324/9781315773155

[23] Feng, Chow Yi, Nur llya Farhana Md Noh, and Ramez Al Mansob. "Study on The Factors and Effects of Noise Pollution at Construction Site in Klang Valley." Journal of Advanced Research in Applied Sciences and Engineering Technology 20, no. 1 (2020): 18-26. https://doi.org/10.37934/araset.20.1.1826

[24] Budiyanto, Muhammad Arif, and Nadhilah Suheriyanto. "Analysis of the Effect of Inlet Velocity on Cooling Speed in a Refrigerated Container using CFD simulations." CFD Letters 12, $\quad$ no. $12 \quad$ (2020): 55-62. https://doi.org/10.37934/cfdl.12.12.5562

[25] Yusefi, Mostafa, Kamyar Shameli, and Ahmad Faris Jumaat. "Preparation and Properties of Magnetic Iron Oxide Nanoparticles for Biomedical Applications: A Brief Review." Journal of Advanced Research in Materials Science 75, no. 1 (2020): 10-18. https://doi.org/10.37934/arms.75.1.1018

[26] Taib, Norhidayah Mat, Mohd Radzi Abu Mansor, and Wan Mohd Faizal Wan Mahmood. "Simulation of Hydrogen Fuel Combustion in Neon-oxygen Circulated Compression Ignition Engine." Journal of Advanced Research in Numerical Heat Transfer 3, no. 1 (2020): 25-36. https://doi.org/10.37934/cfdl.12.12.116

[27] Ohijeagbon, Idehai O., Adekunle A. Adeleke, Vincent T. Mustapha, John A. Olorunmaiye, Imhade P. Okokpujie, and Peter P. Ikubanni. "Development and characterization of wood-polypropylene plastic-cement composite board." Case Studies in Construction Materials 13 (2020): e00365. https://doi.org/10.1016/i.cscm.2020.e00365

[28] Oleolo, Ibrahim, Hayati Abdullah, Maziah Mohamad, Mohammad Nazri Mohd Jaafar, and Akmal Baharain. "Model Selection for the Control of Temperature in a Centralized Air Conditioning System." Journal of Advanced Research in Applied Mechanics 74, no. 1 (2020): 10-20. 